\title{
Insight into the self-aggregation of porphyrins and their influence on asphaltenes aggregation
}

Xuechun Ding, Shengchao Wei, He Bian, Lijun Zhu, Daohong Xia*

State Key Laboratory of Heavy Oil Processing, College of Chemical Engineering, China University of Petroleum (East China), Qingdao 266580, China.

* Corresponding author. E-mail: xiadh@upc.edu.cn (D. Xia)

\section{List of Contents}

S I. Synthesis of TPP, NiTPP and VOTPP.

S II. Calculation of crystal structural parameters of asphaltenes and co-aggregates of asphaltene with porphyrins

S III. Supporting Figures.

Figure S1. Synthesis routes of (a) TPP, (b) NiTPP and (c) VOTPP

Figure S2. (a) UV-Vis spectra and (b) fluorescence spectra of TPP in different solvents; (c) UV-Vis spectra and (d) fluorescence spectra of NiTPP in different solvents; (e) UV-Vis spectra and (f) fluorescence spectra of VOTPP in different solvents.

Figure S3. Effect of different content of TPP on the fluorescence intensity of asphaltene solution with concentration of (a) $100 \mu \mathrm{g} / \mathrm{g}$, (b) $200 \mu \mathrm{g} / \mathrm{g}$ and (c) $300 \mu \mathrm{g} / \mathrm{g}$.

Figure S4. Effect of different content of NiTPP on the fluorescence intensity of asphaltene solution with concentration of (a) $100 \mu \mathrm{g} / \mathrm{g}$ and (b) $200 \mu \mathrm{g} / \mathrm{g}$.

Figure S5. Effect of different content of VOTPP on the fluorescence intensity of asphaltene solution with concentration of (a) $100 \mu \mathrm{g} / \mathrm{g}$ and (b) $200 \mu \mathrm{g} / \mathrm{g}$. 


\section{S I. Synthesis of TPP, NiTPP and VOTPP.}

Figure S1 shows the synthesis route and schematic diagram of tetraphenylporphyrin (TPP), tetraphenylporphyrin (NiTPP) and tetraphenyl vanadyl porphyrin (VOTPP). The synthesis step of TPP is as follows ${ }^{1} .125 \mathrm{~mL}$ of propionic acid and $1.27 \mathrm{~mL}$ of benzaldehyde were added in a $250 \mathrm{~mL}$ of three-necked flask in turn, which was then heated to reflux at a temperature of $140^{\circ} \mathrm{C}$. Next, $0.86 \mathrm{ml}(12.5 \mathrm{mmol})$ of freshly distilled pyrrole was added dropwise to the solution, and the color of the solution changed to black after the dropping. After heating to reflux for 1 hour, the obtained solution was transferred into cool water at a temperature of $4^{\circ} \mathrm{C}$ and stand for $12 \mathrm{~h}$. After filtering the solution, the obtained filter cake was repeatedly washed with hot water and ethanol until the washing liquid is colorless. Subsequently, the purple filter cake was dried in an oven at $78^{\circ} \mathrm{C}$ for $2 \mathrm{~h}$ to obtain purple tetraphenylporphyrin, denoted as TPP with a mass of $0.4065 \mathrm{~g}$ and a yield of $21.1 \%$.

The synthesis of NiTPP was carried out according to the literature method ${ }^{2}$. As shown in Figure S1, $50 \mathrm{~mL}$ of DMF was added in a $250 \mathrm{~mL}$ of three-necked flask, following by heated to reflux at a temperature of $150^{\circ} \mathrm{C}$. Subsequently, $0.2459 \mathrm{~g}(0.4 \mathrm{mmol})$ of TPP and $0.2986 \mathrm{~g}$ (1.2 mmol) of nickel acetate tetrahydrate was added to the solution, which was stirred, heated and refluxed for $0.5 \mathrm{~h}$. After being cooled to room temperature, the flask containing the reaction solution was placed in an ice-water bath for $1 \mathrm{~h}$, which was then added $150 \mathrm{~mL}$ of deionized water in flask. After filtered, the filter cake was repeatedly washed with deionized water until the filtrate was colorless. Finally, the obtained filter cake was vacuum dried at $75^{\circ} \mathrm{C}$ for $3 \mathrm{~h}$ to obtain the red nickel tetraphenylporphyrin, denoted as NiTPP with a mass of 0.2438 $\mathrm{g}$ and a yield of $91 \%$.

The synthesis step of VOTPP is as follows ${ }^{3} .4 \mathrm{~g}$ of phenol was added to a $100 \mathrm{~mL}$ three-necked flask, which was then added $0.5306 \mathrm{~g}(5 \mathrm{mmol})$ of benzaldehyde, $0.3345 \mathrm{~g}$ (5 mmol) of pyrrole, $1.3258 \mathrm{~g}(5 \mathrm{mmol})$ of vanadyl acetylacetonate in turn. After heated at $145^{\circ} \mathrm{C}$ and refluxed for $0.75 \mathrm{~h}$, the reaction solution was cooled to $60^{\circ} \mathrm{C}$, which was then added 30 $\mathrm{mL}$ of sodium hydroxide aqueous solution $(10 w t \%)$. After continuously heated and refluxed for $0.25 \mathrm{~h}$, the reaction solution was filtered. The obtained filter cake was repeatedly washed 
with ethanol until the filtrate was colorless. The filter cake was vacuum dried at $50^{\circ} \mathrm{C}$ for $2 \mathrm{~h}$ to obtain the crude product, which was then separated and further purified by column chromatography with xylene as eluent. The eluent solution containing the first ribbon was transferred to a rotary evaporator operating at $70{ }^{\circ} \mathrm{C}$ for $2 \mathrm{~h}$. Finally, the obtained solid was transferred to a vacuum drying oven and dried at $70^{\circ} \mathrm{C}$ for $3 \mathrm{~h}$ to obtain a red solid powder, denoted as VOTPP with a mass of $0.1693 \mathrm{~g}$ and a yield of $20 \%$.

S II. Calculation of crystal structural parameters of asphaltenes and co-aggregates of asphaltene and porphyrins

The stacking parameters of asphaltene and co-aggregates of asphaltene and porphyrins were calculated from the XRD data as following ${ }^{4-5}$.

(a) The layer distance between aromatic sheets $\left(d_{m}, \mathrm{~nm}\right)$

$$
d_{m}=\frac{\lambda}{2 \sin \theta_{002}}
$$

where $\lambda$ is the wave length of the $\mathrm{Cu} \mathrm{K \alpha}$ radiation and $\theta_{002}$ is the Bragg's angle of 002 peak.

(b) The distance between the saturated portions $\left(d_{\gamma}, \mathrm{nm}\right)$

$$
d_{\gamma}=\frac{5 \lambda}{8 \sin \theta_{002}}
$$

(c) The average height of the stack of the aromatic sheet $\left(L_{c}, \mathrm{~nm}\right)$

$$
L_{\mathrm{c}}=\frac{0.9 \lambda}{\beta_{002} \cos \theta_{002}}
$$

(d) The number of aromatic sheets per stacked nanoaggregate $\left(M_{e}\right)$

$$
M_{\mathrm{e}}=\frac{L_{c}}{d_{m}}+1
$$

S III. Supporting Figures. 
4

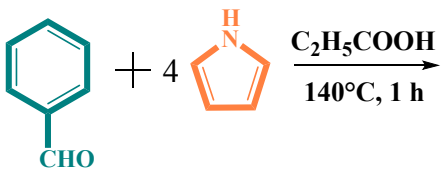

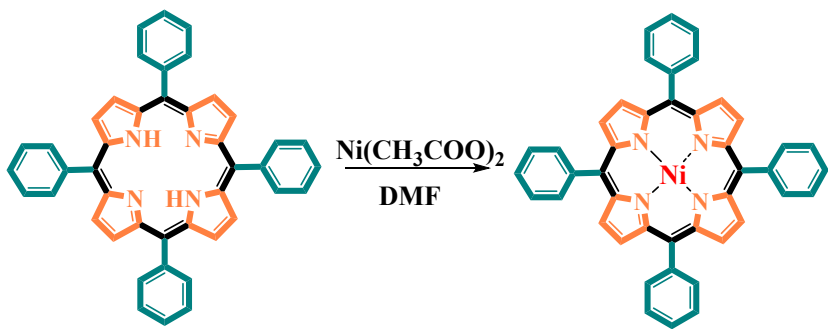

(a)

(b)

4<smiles>O=Cc1ccccc1</smiles><smiles></smiles><smiles>Oc1ccccc1</smiles>

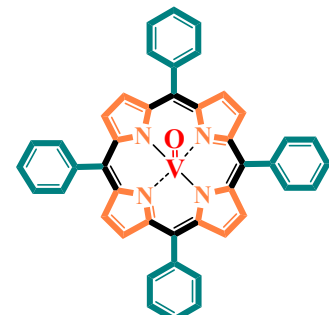

(c)

Figure S1. Synthesis routes of (a) TPP, (b) NiTPP and (c) VOTPP 

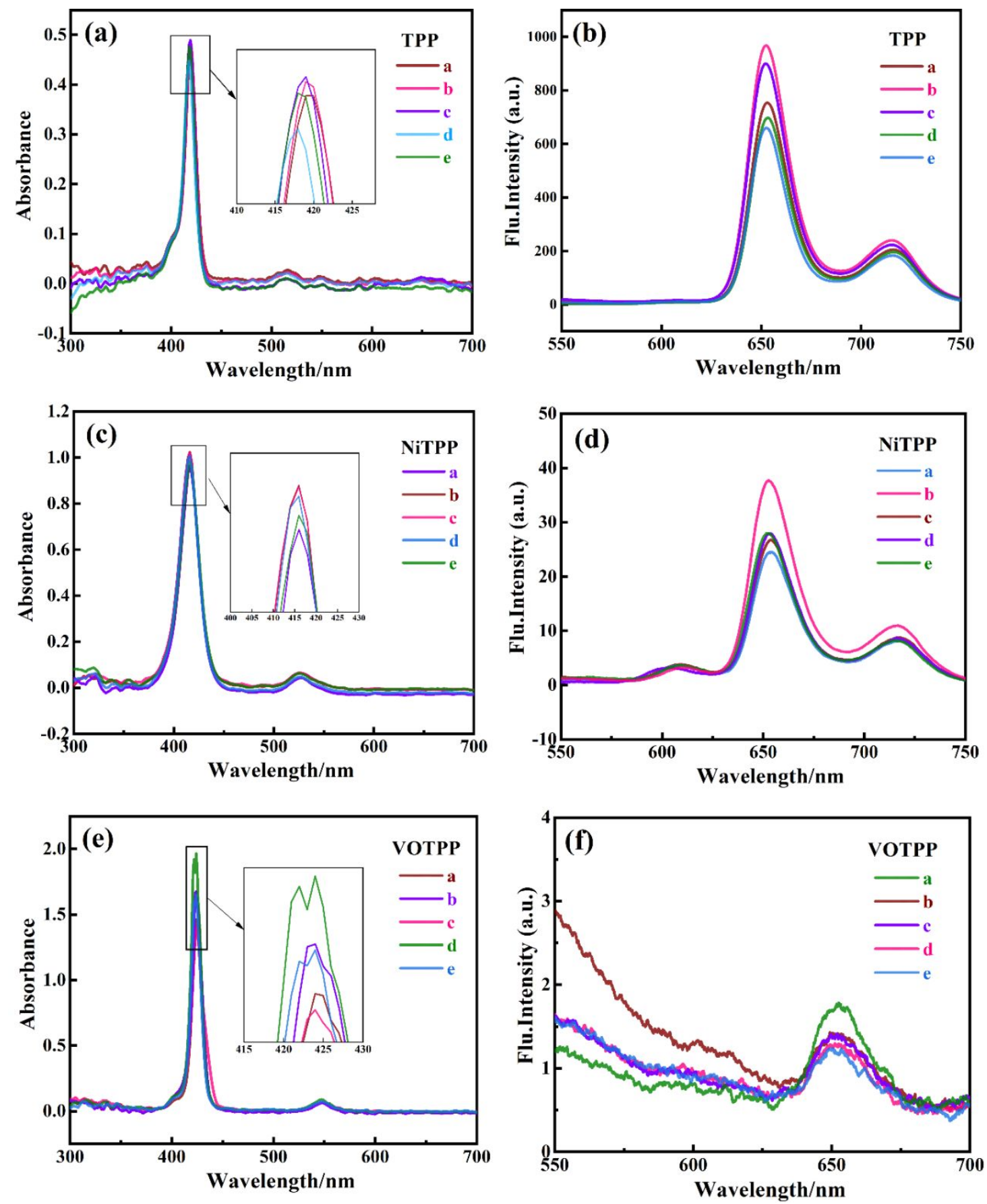

Figure S2. (a) UV-Vis spectra and (b) Fluorescence spectra of TPP in different solvents; (c) UV-Vis spectra and (d) Fluorescence spectra of NiTPP in different solvents; (e) UV-Vis spectra and (f) Fluorescence spectra of VOTPP in different solvents. ((a): toluene; (b): toluene/DMSO; (c): toluene/DMF; (d): toluene/n-heptane; (e): toluene/cyclohexane); The volume ratio of mixed solvents is $1: 1$; the concentration of TPP, NiTPP and VOTPP was $1 \times 10^{-6}, 5 \times 10^{-6}$ and $5 \times 10^{-6} \mathrm{~mol} / \mathrm{L}$; the test temperature was $25^{\circ} \mathrm{C}$. 

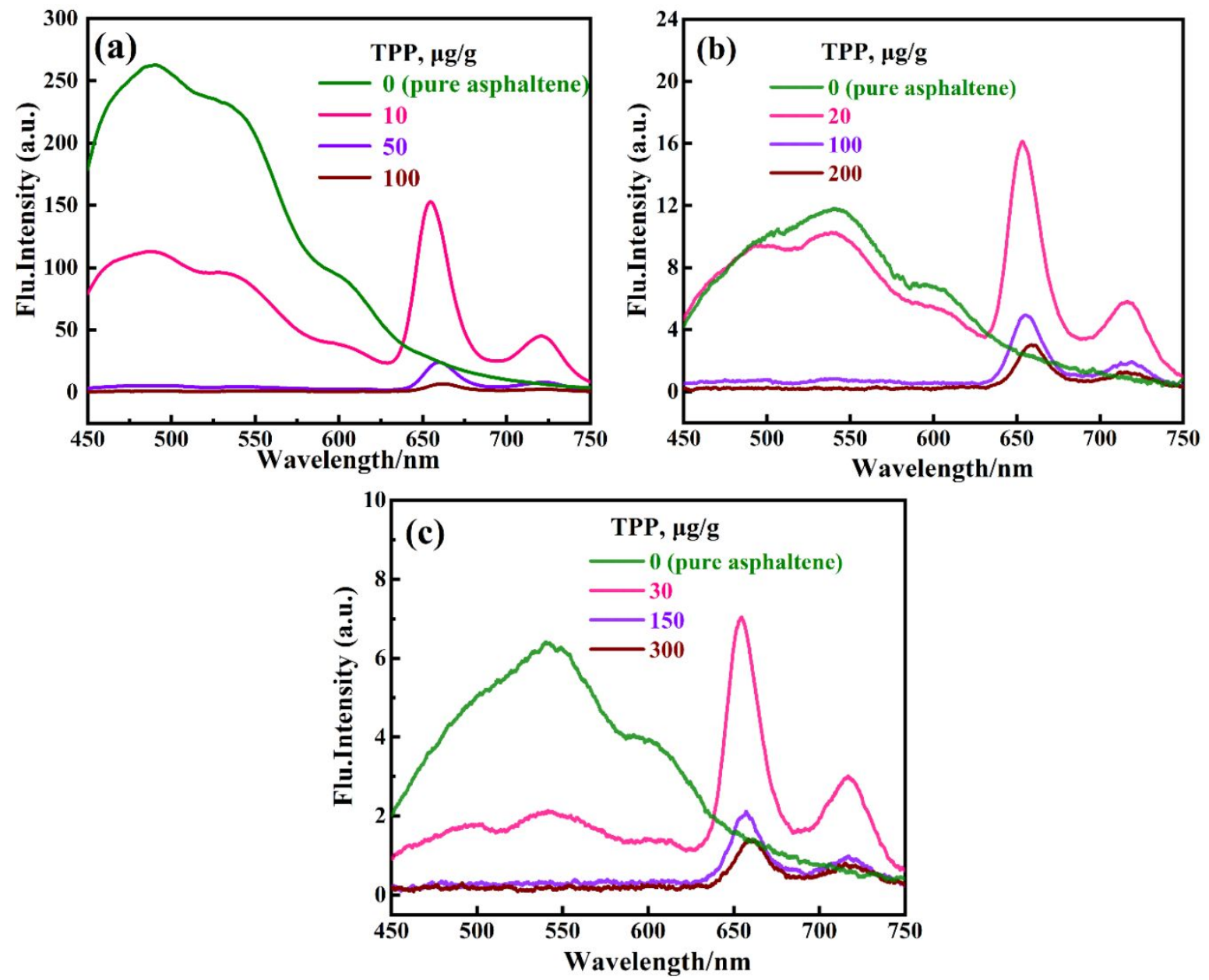

Figure S3. Effect of different content of TPP on the fluorescence intensity of asphaltene solution with concentration of (a) $100 \mu \mathrm{g} / \mathrm{g}$, (b) $200 \mu \mathrm{g} / \mathrm{g}$ and (c) $300 \mu \mathrm{g} / \mathrm{g}$. Measurement condition, solvent toluene, temperature $25^{\circ} \mathrm{C}$, the excitation wavelength was $420 \mathrm{~nm}$ during the fluorescence spectrum test. 

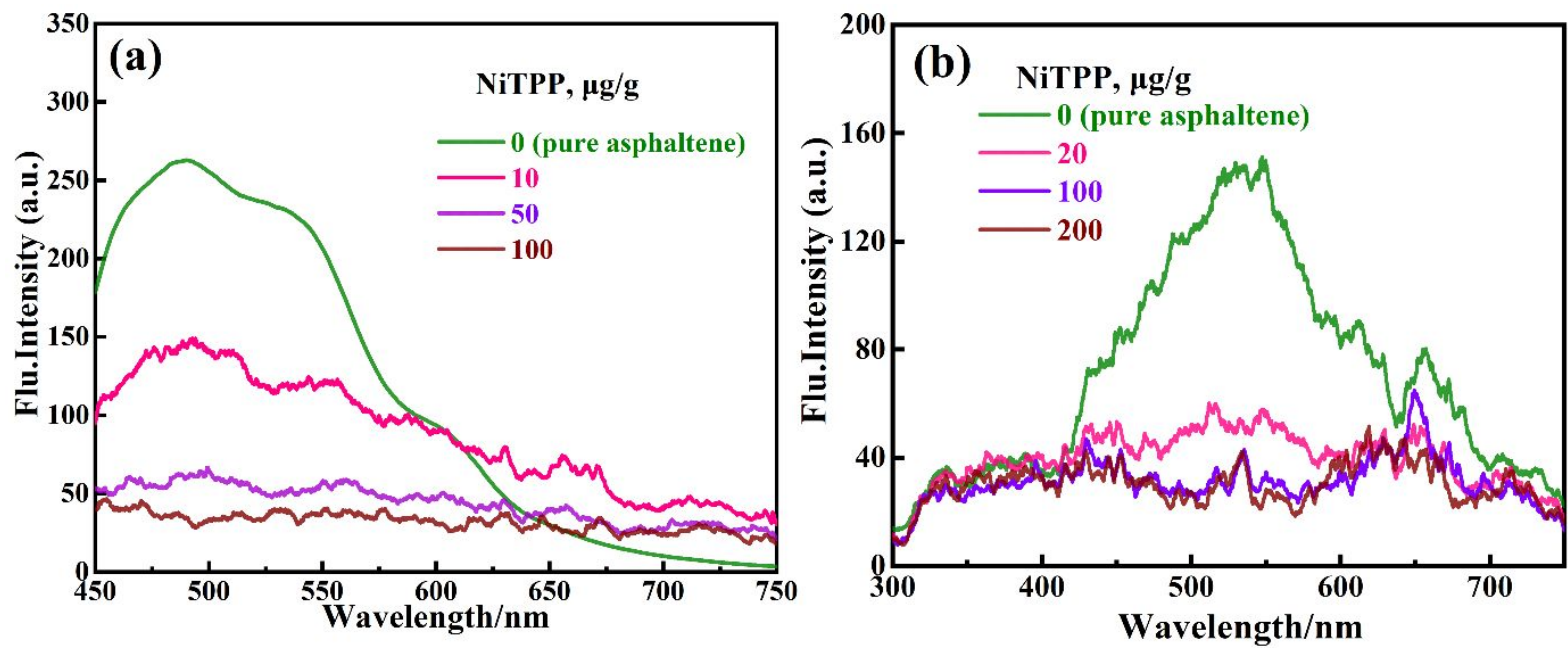

Figure S4. Effect of different content of NiTPP on the fluorescence intensity of asphaltene solution with concentration of (a) $100 \mu \mathrm{g} / \mathrm{g}$ and (b) $200 \mu \mathrm{g} / \mathrm{g}$. Measurement condition, solvent toluene, temperature $25^{\circ} \mathrm{C}$, the excitation wavelength was $420 \mathrm{~nm}$ during the fluorescence spectrum test.
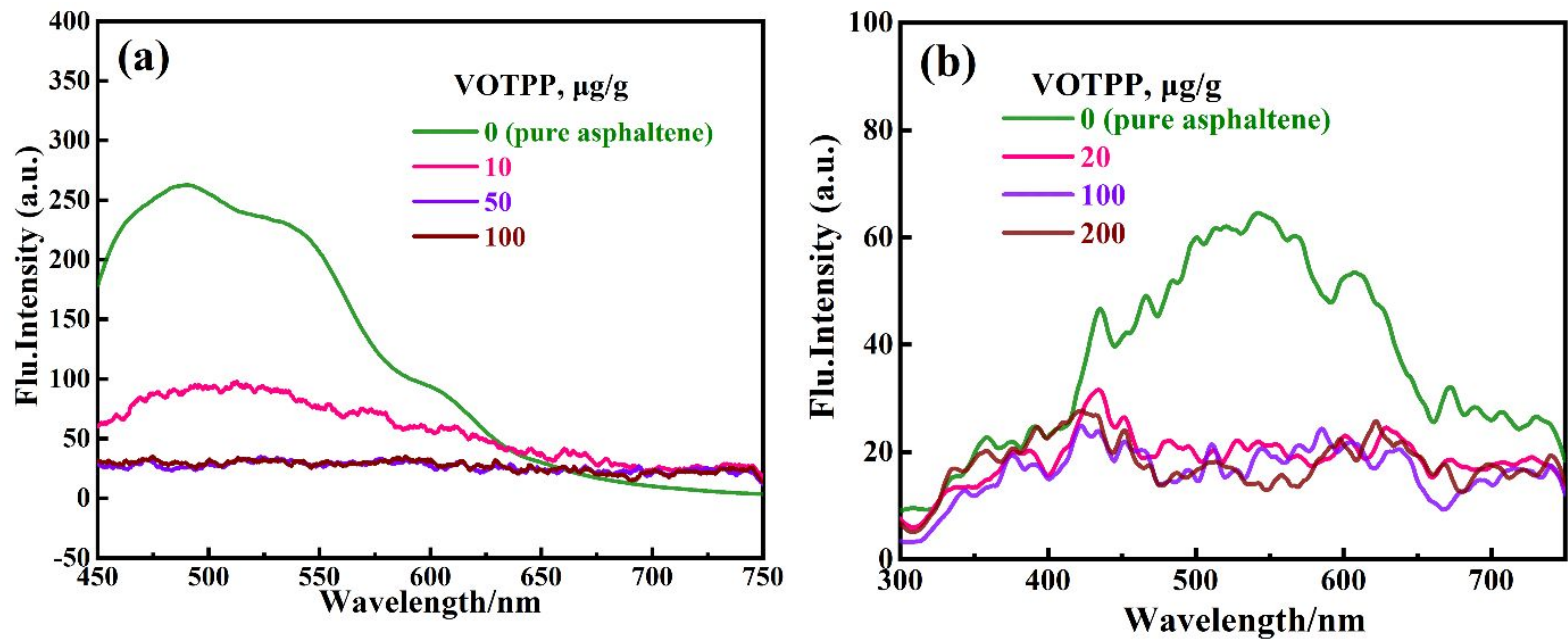

Figure S5. Effect of different content of VOTPP on the fluorescence intensity of asphaltene solution with concentration of (a) $100 \mu \mathrm{g} / \mathrm{g}$ and (b) $200 \mu \mathrm{g} / \mathrm{g}$. Measurement condition, solvent toluene, temperature $25^{\circ} \mathrm{C}$, the excitation wavelength was $420 \mathrm{~nm}$ during the fluorescence spectrum test. 


\section{References}

[1]. Adler, A. D. A simplinfied synthsis for meso-tetralhenyl porphyrins. J. Org. Chem. 1967, $32,467$.

[2]. Adler, A. D.; Longo, F. R.; Kampas, F.; Kim, J. On the preparation of metalloporphyrins. J. Inorg. Nucl. Chem. 1970, 32, 2443-2445.

[3]. Erdman, J. G.; Ramsey, V. G.; Kalenda, N. W.; Hanson, W. E. Synthesis and properties of porphyrin vanadium complexes. J Am Chem Soc 1956, 78 (22), 5844-5847.

[4]. Alhumaidan, F. S.; Hauser, A.; Rana, M. S.; Lababidi, H. M. S.; Behbehani, M. Changes in asphaltene structure during thermal cracking of residual oils: XRD study . Fuel 2015, 150, 558-564.

[5]. Bouhadda, Y.; Bormann, D.; Sheu, E.; Bendedouch, D.; Krallafa, A.; Daaou, M. Characterization of Algerian Hassi-Messaoud asphaltene structure using Raman spectr ometry and X-ray diffraction. Fuel 2007, 86 (12-13), 1855-1864. 